\title{
Advanced Electrical Materials and Components Development-An Update
}

Gene E. Schwarze

Glenn Research Center, Cleveland, Ohio 
Since its founding, NASA has been dedicated to the advancement of aeronautics and space science. The NASA Scientific and Technical Information (STI) Program Office plays a key part in helping NASA maintain this important role.

The NASA STI Program Office is operated by Langley Research Center, the Lead Center for NASA's scientific and technical information. The NASA STI Program Office provides access to the NASA STI Database, the largest collection of aeronautical and space science STI in the world. The Program Office is also NASA's institutional mechanism for disseminating the results of its research and development activities. These results are published by NASA in the NASA STI Report Series, which includes the following report types:

- $\quad$ TECHNICAL PUBLICATION. Reports of completed research or a major significant phase of research that present the results of NASA programs and include extensive data or theoretical analysis. Includes compilations of significant scientific and technical data and information deemed to be of continuing reference value. NASA's counterpart of peerreviewed formal professional papers but has less stringent limitations on manuscript length and extent of graphic presentations.

- TECHNICAL MEMORANDUM. Scientific and technical findings that are preliminary or of specialized interest, e.g., quick release reports, working papers, and bibliographies that contain minimal annotation. Does not contain extensive analysis.

- CONTRACTOR REPORT. Scientific and technical findings by NASA-sponsored contractors and grantees.
- CONFERENCE PUBLICATION. Collected papers from scientific and technical conferences, symposia, seminars, or other meetings sponsored or cosponsored by NASA.

- SPECIAL PUBLICATION. Scientific, technical, or historical information from NASA programs, projects, and missions, often concerned with subjects having substantial public interest.

- TECHNICAL TRANSLATION. Englishlanguage translations of foreign scientific and technical material pertinent to NASA's mission.

Specialized services that complement the STI Program Office's diverse offerings include creating custom thesauri, building customized databases, organizing and publishing research results ... even providing videos.

For more information about the NASA STI Program Office, see the following:

- Access the NASA STI Program Home Page at http://www.sti.nasa.gov

- E-mail your question via the Internet to help@sti.nasa.gov

- Fax your question to the NASA Access Help Desk at 301-621-0134

- Telephone the NASA Access Help Desk at 301-621-0390

- Write to:

NASA Access Help Desk

NASA Center for AeroSpace Information 7121 Standard Drive

Hanover, MD 21076 
NASA/TM-2005-214050

AIAA-2005-5717

\section{Advanced Electrical Materials and Components Development-An Update}

Gene E. Schwarze

Glenn Research Center, Cleveland, Ohio

Prepared for the

Third International Energy Conversion Engineering Conference

sponsored by the American Institute of Aeronautics and Astronautics

San Francisco, California, August 15-18, 2005

National Aeronautics and

Space Administration

Glenn Research Center 


\section{Acknowledgments}

The author would like to acknowledge the NASA Energetics Project of the Enabling Concepts and Technologies Program for funding this research.

Trade names or manufacturers' names are used in this report for identification only. This usage does not constitute an official endorsement, either expressed or implied, by the National Aeronautics and Space Administration.

Available from

NASA Center for Aerospace Information 7121 Standard Drive

Hanover, MD 21076
National Technical Information Service 5285 Port Royal Road Springfield, VA 22100

Available electronically at http:/ /gltrs.grc.nasa.gov 


\title{
Advanced Electrical Materials and Components Development-An Update
}

\author{
Gene E. Schwarze \\ National Aeronautics and Space Administration \\ Glenn Research Center \\ Cleveland, Ohio 44135
}

\begin{abstract}
The primary means to develop advanced electrical components is to develop new and improved materials for magnetic components (transformers, inductors, etc.), capacitors, and semiconductor switches and diodes. This paper will give an update of the Advanced Power Electronics and Components Technology being developed by the NASA Glenn Research Center for use in future Power Management and Distribution subsystems used in space power systems for spacecraft and lunar and planetary surface power. The initial description and status of this technology program was presented two years ago at the First International Energy Conversion Engineering Conference held at Portsmouth, Virginia, August 2003 (ref. 1). The present paper will give a brief background of the previous work reported and a summary of research performed the past several years on soft magnetic materials characterization, dielectric materials and capacitor developments, high quality silicon carbide atomically smooth substrates, and $\mathrm{SiC}$ static and dynamic device characterization under elevated temperature conditions. The rationale for and the benefits of developing advanced electrical materials and components for the PMAD subsystem and also for the total power system will also be briefly discussed.
\end{abstract}

\section{Introduction}

The NASA Glen Research Center (GRC) has for many years led the technology development of advanced electrical and electronic materials and components for Power Management and Distribution (PMAD) applications. All aerospace systems require PMAD between the energy/power source and the loads. The PMAD subsystem can be broadly described as the conditioning and control of unregulated power from the energy source and its transmission to a power bus for distribution to the intended loads. All power and control circuits for PMAD require electrical components for switching, rectification, energy storage, voltage/current transformation, filtering, regulation, protection, and isolation. In order to increase the power density, efficiency, operating temperature and reliability of the PMAD subsystem requires advances in electrical component technology. The primary means to develop advanced electrical components is to develop new and significantly improved materials for magnetic components such as transformers and inductors, capacitors, and semiconductor switches and diodes.

The specific benefits of developing advanced electrical materials and component technology are:

1. Higher operating frequency components give increased power density by reducing the mass and volume of the passive components (transformers, inductors, and filter capacitors). But increasing the frequency does have its downside: switching and diode losses can increase along with loss increases in the magnetic components and capacitors. The result is a decrease in efficiency.

2. Higher operating temperature components give reduced cooling requirements and thus reduce the complexity, size, and mass of the thermal transport and radiator subsystem.

3. Higher efficiency components not only give reduced cooling requirements but they also reduce the power generation and storage needs for a given output power.

4. Higher radiation resistant components give reduced mass and volume of shielding materials.

5. Higher voltage components give higher power systems and give reduced power transmission cable mass.

From a power system perspective, the benefits of developing advanced electrical components include:

1. Increased payload capability

2. Decreased spacecraft mass/volume/cost

3. Increased design flexibility

4. Increased reliability 
GRC has the responsibility for the development of advanced electrical and electronic materials and components under the Advanced Electrical Components Technology Task. This task is being funded under NASA's Energetics Project and Small Business Innovative Research Program. The present focus of this research task is on the following four areas:

1. New and significantly improved high frequency, high/wide temperature, low loss soft magnetic materials for the development of magnetic components (transformers, inductors, chokes, etc.) with increased power/energy density, electrical efficiency, maximum operating temperature, and temperature range.

2. New and/or significantly improved electrical insulating materials such as magnet wire insulation, inter-layer insulation, etc for high/wide temperature magnetic components.

3. New and significantly improved dielectric materials for the development of power capacitors with increased volumetric efficiency, electrical efficiency, energy density, maximum operating temperature, and temperature range.

4. Development of test circuits, fixtures and measurement systems to characterize $\mathrm{SiC}$ diodes and switches under both static and dynamic conditions at high voltage and elevated temperatures.

An overview of the in-house and sponsored work performed under the Advanced Electrical Component Technology Task was given at the First International Energy Conversion and Engineering Conference (IECEC 2005) (ref. 1). The present paper will give a brief background of the previous work and an update of research performed the past several years.

\section{Soft Magnetic Materials}

The magnetic properties of matter are classified as diamagnetic, paramagnetic, ferromagnetic, ferrimagnetic, and antiferromagnetic. Only ferromagnetic and ferrimagnetic materials are of interest to the magnetic component designer. Ferromagnetic materials include iron, cobalt, nickel, their alloys, and some of the rare-earth metals. Ferrimagnetic substances are oxides and mixtures of oxides of ferromagnetic metals and these materials are called ferrites. Ferromagnetic and ferrimagnetic materials are made up of small regions of magnetization called domains. The intensity of magnetization, that is, the magnetic moment per unit volume of each domain is equivalent to the saturation or intrinsic magnetization of the bulk material. The magnetic flux density or induction below saturation is determined by the orientation of the magnetic moment of the domains with respect to the applied magnetizing field.

Ferromagnetic and ferrimagnetic materials are of two types; hard and soft. Hard materials require a large magnetizing field for the material to magnetically saturate, and as a result, once magnetized, these materials have a very large intrinsic coercivity and become permanent magnets. Soft magnetic materials require very small magnetizing fields to become magnetically saturated, have a low coercivity, and once the magnetizing field is removed, the flux density essentially goes to zero. NASA GRC has research programs in both hard and soft magnetic materials but only soft magnetic materials will be discussed in this paper.

The designer of power magnetic components requires specific knowledge about the electrical, magnetic, and thermal properties of the soft magnetic materials used in these components. The desired properties of soft magnetic materials are listed in table 1 . The chances of finding all these desirable properties in any given magnetic material are quite slim so the magnetic component designer must usually perform a trade-off design analysis to select the best material to meet specific design requirements.

A major consideration in power magnetic component design is the core loss. Core loss is the power dissipated in a magnetic material and the classical or conventional approach separates the core loss into hysteresis and eddy current loss components. Hysteresis loss is defined as the energy (heat) expended in a magnetic material as a result of magnetic irreversibility (hysteresis) when the flux density is cyclic. The area of the dc or static B-H hysteresis loop is proportional to the hysteresis loss. The material processing procedure which includes both the type of heat and magnetic anneals determines the shape of the static loop. The eddy current loss is the energy (heat) expended by the circulating (eddy) currents induced through the time variation of the magnetic flux in the core laminations or the convolutions of tape wound cores. The area of the ac or dynamic B-H hysteresis loop gives a qualitative assessment of the core loss. The core loss is a function of several variables which include type of material, lamination or tape thickness, peak operating flux density, operating frequency, operating temperature, type of excitation (voltage or current), and excitation waveform (sine, square, etc.).

Our present soft magnetic materials program is focused on the investigation, characterization, and evaluation of amorphous, nanocrystalline, nanocomposite and very thin tape polycrystalline magnetic materials. This research 
includes both in-house and sponsored research and a brief description of this work will now be given. Amorphous metal or metallic glass is characterized by the absence of any long-range atomic order. Amorphous alloys have no crystalline structure and are therefore isotropic. This isotropy coupled with engineered induced anisotropies allows the amorphous magnetic alloys to exhibit soft magnetic properties with low core loss.

TABLE 1.-DESIRED SOFT MAGNETIC MATERIAL PROPERTIES

\begin{tabular}{|c|c|c|}
\hline $\begin{array}{ll} & \text { High power/energy density } \\
\text { - } & \text { High saturation flux density, } \mathrm{B}_{\mathrm{s}} \\
\text { - } & \text { Flat } \mathrm{B}_{\mathrm{s}} \text { versus } \mathrm{T} \text { curve over wide } \\
\text { temperature range }\end{array}$ & \begin{tabular}{ll} 
& \multicolumn{1}{c}{ High temperature } \\
- & High curie temperature \\
- & High thermal conductivity \\
- & Stable characteristics under \\
temperature cycling \\
- $\quad$ Stable characteristics at high \\
temperature \\
- $\quad$ Predictable aging effects
\end{tabular} & $\begin{array}{l}\text { High efficiency } \\
\text { - } \quad \text { Low coercive force } \\
\text { - } \quad \text { High permeability at operating flux } \\
\text { density } \\
\text { - } \quad \text { Low core loss at operating } \\
\text { Frequency and temperature }\end{array}$ \\
\hline
\end{tabular}

Nanocrystalline magnetic materials are produced by partial crystallization of an amorphous alloy which contains elements not allowing complete crystallization. The characteristic feature of a nanocrystalline material is a twophase structure in which fine crystalline grains with dimensions on the order of 10 to $20 \mathrm{~nm}$ are embedded in an amorphous intergranular phase. Nanocomposite magnetic materials are fabricated by the compaction of insulated, magnetic nanoparticles of dimensions generally less than $50 \mathrm{~nm}$.

Over the past decade NASA GRC has developed in-house a unique measurement system to characterize the core loss and both the static and dynamic B-H hysteresis loops of both inductor and transformer types of soft magnetic materials. Presently the system is capable of making measurements over the temperature range of -150 to $300{ }^{\circ} \mathrm{C}$, peak flux densities to saturation, frequencies up to $1 \mathrm{MHz}$, and for sine and square wave voltage excitation. An extensive specific core loss (SCL) and static and dynamic B-H hysteresis loop database has been developed and published for polycrystalline alloys (refs. 2 to 5) amorphous alloys (refs. 2 and 6) nanocrystalline alloy (refs. 6) and power ferrites (refs. 7).

The polycrystalline magnetic alloys (refs. 2 to 5) previously investigated were all 1-mil thick tape wound toroids. This investigation showed that the Nickel(Ni)-Iron(Fe)-Molybdenum(Mo) alloy of nominal chemical composition of $79 \% \mathrm{Ni}, 19 \% \mathrm{Fe}$, and $4 \% \mathrm{Mo}$ by weight (ref. 8 ) had very low core loss for frequencies up to $50 \mathrm{kHz}$ and temperatures up to $300{ }^{\circ} \mathrm{C}$ (4). In the soft magnetic materials community, this nominal composition is referred to by various names. For example, Magnetics, A Division of Spang, fabricates Round Permalloy 80, Square Permalloy 80, and Supermalloy tape wound cores while Arnold Engineering Company fabricates 4-79 Permalloy, Square Permalloy, and Supermalloy tape wound cores. The difference in the magnetic and electrical properties of the "Permalloy" type of magnetic materials is determined by the impurities present, trace elements added, and the heat treatment and magnetic anneals used in processing the material to its final thickness.

As previously mentioned, the core loss is a function of lamination or tape thickness so it was decided to investigate the effect of tape thickness on the core loss for the "Permalloy" type of magnetic material. The test cores for this investigation were $1,1 / 2,1 / 4$, and 1/8-mil thick tapes wound on ceramic bobbin cores. Room temperature data for each test core were taken over the frequency range of 10 to $750 \mathrm{kHz}$ for sine wave voltage excitation. The test results showed that the 1/4-mil thick tape gave the lowest specific core loss. The complete details of this investigation were presented in a paper (ref. 9) given at IECEC 2004. A grant was recently awarded to the University of Pittsburgh at Johnstown (UPJ) to investigate the effects of temperature (up to $300{ }^{\circ} \mathrm{C}$ ) and frequency (up to $1 \mathrm{MHz}$ ) for both sine and square wave voltage excitation on these very thin tapes.

Much of the present interest in nanocrystalline and nanocomposite materials has to do with the results published in papers by G. Herzer (refs. 10 and 11). These papers give a graphical comparison of several types of magnetic materials by showing the dependence of the coercivity on the material's grain size. The magnetic materials in this comparison include an amorphous Co-based alloy, nanocrystalline Fe-based alloys, and 50-50 NiFe and 80-20 NiFe polycrystalline alloys. The coercivity versus grain size graph shows that polycrystalline $80-20 \mathrm{NiFe}$ alloys have coercivities in the range of 5 to $0.5 \mathrm{~A} / \mathrm{m}$ for grain sizes in the range of 50 to $100 \mu \mathrm{m}$, respectively, i.e., the larger grain size has the lower coercivity. The 50-50 NiFe alloys with grain sizes in the range of 10 to $100 \mu \mathrm{m}$ have coercivities in the range of 100 to $5 \mathrm{~A} / \mathrm{m}$. As an Fe-based nanocrystalline alloy approaches a grain size around $100 \mathrm{~nm}$, the coercivity plateaus at around $5000 \mathrm{~A} / \mathrm{m}$ and then proceeds to decrease rapidly to coercivities less than $1 \mathrm{~A} / \mathrm{m}$ for Fe-based nanocrystalline materials with grain sizes on the order of 10 to $20 \mathrm{~nm}$. The Co-based amorphous alloy with a grain size of less than $1 \mathrm{~nm}$ has a coercivity of about $0.5 \mathrm{~A} / \mathrm{m}$ which is about the same as the polycrystalline $80-20 \mathrm{NiFe}$ alloy with grain size of $100 \mu \mathrm{m}$. 
The dc coercivity is a measure of the hysteresis loss so the question arises as to why the nanocrystalline and nanocomposite magnetic alloys are of interest if their coercivities are equal or greater than the $80-20 \mathrm{NiFe}$ alloy coercivities. For nanocrystalline alloys the reason is they contain non-metallic elements such as $\mathrm{Si}$ and B and these additives greatly increase the resistivity. In the case of nanocomposite magnetic materials, the resistivity should be high because the magnetic nanoparticles are coated with an electrical insulator. Polycrystalline magnetic alloys have low resistivities and small additions of non-magnetic elements are added to increase their resistivities. For example, the polycrystalline Supermalloy alloy with Mo added to give Supermalloy a resistivity of $57 \mu \Omega \mathrm{cm}$ (ref. 8). The Febased Vacuumschmelze nanocrystalline alloy, Vitroperm $500^{\circ} \mathrm{F}$, has a resistivity of $115 \mu \Omega \mathrm{cm}$ (ref. 12), which is a 2 times increase over Supermalloy.

NASA has sponsored both nanocrystalline and nanocomposite magnetic materials experimental research investigations. The nanocrystalline research was conducted through (1) in-house research investigations, (2) grants with UPJ, and (3) in collaboration with the Department of Materials Science and Engineering, Carnegie Mellon University (CMU) under the NASA Graduate Student Research Program (GSRP). The CMU work was part of a $\mathrm{Ph} . \mathrm{D}$. thesis project. The thesis "High-temperature and frequency-dependent properties and structural evolution of HITPERM, a FeCo-base nanocomposite soft ferromagnetic material" was completed in December 2003. The nanocomposite research is being conducted under two Phase II Small Business Innovative Research (SBIR) awards.

The in-house research investigated both amorphous and nanocrystalline magnetic alloys. The amorphous alloys investigated were the Cobalt-based Vacuumschmelze VITROVAC ${ }^{\circledR} 6025$ and $6030^{\circ} \mathrm{F}$ materials (refs. 6 and 13). The core loss investigation was conducted at $100 \mathrm{kHz}$ for sine wave voltage excitation over a temperature range of -150 to $150{ }^{\circ} \mathrm{C}$. The $6030^{\circ} \mathrm{F}$ has a saturation induction, $\mathrm{B}_{\mathrm{S}}$, of $0.80 \mathrm{~T}$ while the $\mathrm{B}_{\mathrm{S}}$ of 6025 is $0.55 \mathrm{~T}$. $6035^{\circ} \mathrm{F}$ has a Curie temperature of $350^{\circ} \mathrm{C}$ compared to $210^{\circ} \mathrm{C}$ for $6025^{\circ} \mathrm{F}$. Both of these materials are transverse magnetically field annealed. Amorphous magnetic materials are usually processed using two different types of magnetic field anneals: a longitudinal or a transverse magnetic field anneal. The longitudinal field anneal is applied parallel to the rolling direction and in the plane of the magnetic tape while the transverse field anneal is applied perpendicular to the rolling direction and in the plane of the tape. A transverse anneal tens to promote rotational reversible magnetization process with the B-H hysteresis loop slanted or skewed to the right of a longitudinal field annealed material.

The nanocrystalline material investigated in-house was Vacuumschmelze VITROPERM ${ }^{\circledR} 500^{\circ} \mathrm{F}$ which is an Iron-based material with $\mathrm{B}_{\mathrm{S}}=1.2 \mathrm{~T}$ and Curie temperature of $600^{\circ} \mathrm{C}$. VITROPERM ${ }^{\circledR}$ is an amorphous material when it is first manufactured. Annealing of this material at a specified temperature produces a nanocrystalline two phase structure. The two-phase structure has a fine crystalline grain of mean-diameter 10 to $20 \mathrm{~nm}$, which is embedded in an amorphous residual phase (ref. 12). The manufacture's literature does not indicate whether a magnetic field is applied during the thermal anneal.

A comparison of the specific core loss, SCL, for 6025 (amorphous), $500^{\circ} \mathrm{F}$ (nanocrysralline), and two different tape thicknesses of Supermalloy (polycrystalline) for various maximum magnetic flux densities, $\mathrm{B}_{\mathrm{M}}$, at frequency of $100 \mathrm{kHz}$ is given in table 2. Also included for comparison is a power ferrite solid toroidal core provided by Ceramic Magnetics and designated as MN8CX. The SCL data for the MN8CX comes from an in-house investigation of this material (ref. 7). This table shows that the amorphous material, $6025^{\circ} \mathrm{F}$, has the lowest SCL for all three flux densities followed by the nanocrystalline, $500^{\circ} \mathrm{F}$, and the $6.35 \mu \mathrm{m}$ thick tape polycrystalline material, Supermalloy. The power ferrite has a low SCL at $0.1 \mathrm{~T}$ but then climbs rapidly with increasing $\mathrm{B}_{\mathrm{M}}$. Table 2 clearly shows the effect of tape thickness on the SCL for the Supermalloy material. The $25.4 \mu \mathrm{m}$ thick tape Supermalloy material is more than 3 times the SCL for the $6.35 \mu \mathrm{m}$ sample for all flux densities shown. Also, a comparison of the $23 \mu \mathrm{m}$ thick tape amorphous material, $6025^{\circ} \mathrm{F}$, with the $25.4 \mu \mathrm{m}$ thick tape polycrystalline material, Supermalloy, clearly shows that the SCL of the amorphous material is far superior to the polycrystalline material by a factor of more than 4.

Table 3 shows the effect of frequency on the SCL for the same three materials given in table 2. For all three frequencies shown, the SCL of the amorphous material $\left(6025^{\circ} \mathrm{F}\right)$ is the lowest but now the $6.35 \mu \mathrm{m}$ thick tape polycrystalline material (Supermalloy) is a close competitor at $300 \mathrm{kHz}$. The nanocrystalline $\left(500^{\circ} \mathrm{F}\right)$ and power ferrite (MN8CX) materials have similar SCL and again, the $25.4 \mu \mathrm{m}$ thick tape polycrystalline material has the highest SCL. 
TABLE 2.-COMPARISON OF THE SPECIFIC CORE LOSS FOR A POLYCRYSTALLINE (SUPERMALLOY), AMORPHOUS $\left(6025^{\circ} \mathrm{F}\right)$, NANOCRYSTALLINE $\left(500^{\circ} \mathrm{F}\right)$, AND FERRITE (MN8CX) FOR VARIOUS FLUX DENSITIES AT $100 \mathrm{KHZ}$ AND $25^{\circ} \mathrm{C}$ EXCEPT WHERE NOTED

\begin{tabular}{|c|c|c|c|c|c|}
\hline \multicolumn{6}{|c|}{ Specific core loss (w/lb) at $\mathbf{1 0 0} \mathbf{~ k H z}$ and 25 ${ }^{\circ} \mathbf{C}$ except where noted } \\
\hline $\begin{array}{c}\text { Max flux density } \\
(\mathbf{T})\end{array}$ & $\mathbf{6 0 2 5}^{\circ} \mathbf{F}$ & $\begin{array}{c}\mathbf{5 0 0}^{\circ} \mathbf{F} \\
\left(\mathbf{5 0}^{\circ} \mathbf{C}\right)\end{array}$ & Supermalloy & Supermalloy & MN8CX \\
\hline & $(23 \mu \mathrm{m}$ tape) & $(23 \mu \mathrm{m}$ tape $)$ & $(25.4 \mu \mathrm{m}$ tape) & $(6.35 \mu \mathrm{m}$ tape) & (Solid) \\
\hline 0.1 & 3.0 & 4.0 & 14.6 & 4.1 & 4.8 \\
\hline 0.2 & 12.2 & 15.9 & 54.4 & 17.0 & 33.7 \\
\hline 0.3 & 28.8 & 35.7 & 119 & 37.9 & 98.0 \\
\hline
\end{tabular}

TABLE 3.-COMPARISON OF THE SPECIFIC CORE LOSS OF A POLYCRYSTALLINE (SUPERMALLOY), AMORPHOUS $\left(6025^{\circ} \mathrm{F}\right)$, NANOCRYSTALLINE $\left(500^{\circ} \mathrm{F}\right)$, AND FERRITE (MN8CX) MAGNETIC MATERIAL AT VARIOUS FREQUENCIES AT $0.1 \mathrm{~T}$ AND $25^{\circ} \mathrm{C}$ EXCEPT WHERE NOTED

\begin{tabular}{|c|c|c|c|c|c|}
\hline \multicolumn{6}{|c|}{ Specific core loss (w/lb) at $\mathbf{0 . 1} \mathbf{~}$ and 25 ${ }^{\circ} \mathbf{C}$ except where noted } \\
\hline $\begin{array}{c}\text { Frequency } \\
(\mathbf{k H z})\end{array}$ & $\mathbf{6 0 2 5}^{\circ} \mathbf{F}$ & $\begin{array}{c}\mathbf{5 0 0}^{\circ} \mathbf{F} \\
\left(\mathbf{5 0}^{\circ} \mathbf{C}\right)\end{array}$ & Supermalloy & Supermalloy & MN8CX \\
\hline & $(23 \mu \mathrm{m}$ tape) & $(23 \mu \mathrm{m}$ tape $)$ & $(25.4 \mu \mathrm{m}$ tape) & $(6.35 \mu \mathrm{m}$ tape $)$ & (Solid) \\
\hline 100 & 3.0 & 4.0 & 14.6 & 4.1 & 4.8 \\
\hline 200 & 9.9 & 14.8 & No data & No data & 14.6 \\
\hline 300 & 19.8 & 30.6 & 94.2 & 22.0 & 32.2 \\
\hline
\end{tabular}

As previously discussed the core loss is the sum of the hysteresis and eddy current loss. Classical theory shows that the eddy current loss is inversely proportional to the resistivity. So by increasing the resistivity, the core loss of a nanocrystalline or nanocomposite magnetic alloy can be much lower than a polycrystalline alloy with dc coercivities about the same as for a nanocrystalline or nanocomposite alloy. Table 2 shows that the SCL of the $25.4 \mu \mathrm{m}$ thick tape polycrystalline alloy (Supermalloy) is more than 3 times the SCL of the $23 \mu \mathrm{m}$ thick tape Ironbased nanocrystalline alloy $\left(500^{\circ} \mathrm{F}\right)$. However, by reducing the tape thickness of the polycrystalline alloy from 25.4 to $6.35 \mu \mathrm{m}$, then the SCL of the Iron-based nanocrystalline $\left(500^{\circ} \mathrm{F}\right)$ and polycrystalline (Supermalloy) alloy become almost equal for $100 \mathrm{kHz}$ over the range of $\mathrm{B}_{\mathrm{M}}$ 's investigated.

From a core loss consideration, the data in tables 2 and 3 show that the amorphous material $\left(6025^{\circ} \mathrm{F}\right)$ would most likely be the material of choice by the magnetic components designer if minimum core loss was a design requirement. The data in tables 2 and 3 also provide a technical basis against which the SCL of new nanocrystalline and nanocomposite magnetic materials can be compared to determine whether they will be competitive with presently available magnetic materials. Two cobalt-based amorphous alloys, Metglas ${ }^{\circledR} 2714 \mathrm{~A}$ and Metglas ${ }^{\circledR}$ $2714 \mathrm{AF}$, were recently experimentally investigated and this work will be presented at IECEC 2005 (ref. 14). The reason for selecting these two materials was not only to compare to previously investigated Cobalt-based amorphous alloys, but more importantly to enable a comparison of a longitudinal (2714 A) to a transverse (2714 AF) magnetic field annealed alloy. The composition of these two alloys is basically the same with the only difference being in the annealing process (refs. 15 and 16).

The electrical and magnetic characteristics of the longitudinal annealed 2714 A were investigated over the frequency range of 1 to $200 \mathrm{kHz}$ and temperature range of 23 to $150{ }^{\circ} \mathrm{C}$ for both sine and square wave voltage excitation. The specific core loss was lower for the square than the sine wave voltage excitation for the same maximum flux density, frequency, and temperature. The electrical and magnetic characteristics of the transverse magnetic field annealed $2714 \mathrm{AF}$ were investigated over the frequency range of 10 to $200 \mathrm{kHz}$ for sine wave voltage excitation and $23{ }^{\circ} \mathrm{C}$ only. $200 \mathrm{kHz}$ for sine wave voltage excitation and $23{ }^{\circ} \mathrm{C}$ only. A comparison of $2174 \mathrm{~A}$ to $2714 \mathrm{AF}$ found that $2714 \mathrm{AF}$ always had lower specific core loss than $2714 \mathrm{~A}$ for any given magnetic flux density and frequency and the ratio of specific core loss of $2714 \mathrm{~A}$ to $2714 \mathrm{AF}$ was dependent on both magnetic flux density and frequency. A comparison was also made of the $2714 \mathrm{~A}, 2714 \mathrm{AF}$, and $6025^{\circ} \mathrm{F}$ materials to two different tape thicknesses of the polycrystalline Supermalloy material and the results show that $2714 \mathrm{AF}$ and $6025^{\circ} \mathrm{F}$ have the lowest specific core loss at $100 \mathrm{kHz}$ over the magnetic flux density range of 0.1 to $0.4 \mathrm{~T}$.

The objective of the nanocrystalline work with CMU was to develop a high temperature $\left(600^{\circ} \mathrm{C}\right)$ nanocrystalline alloy with high saturation induction and low core loss. This research built on the new class of nanocrystalline magnetic alloys (refs. 17 and 18) developed by CMU. These alloys with a composition of (Fe, $\mathrm{Co}$ )-M-B-Cu (where $\mathrm{M}=\mathrm{Zr}$ and $\mathrm{Hf}$ ) have been named HITPERM. The HITPERM alloys are synthesized through partial recrystallization of amorphous precursors. The HITPERM class of nanocrystalline magnetic alloys shows a large magnetic induction at elevated temperature but the core loss is relatively high compared to other commercial 
nanocrystalline alloys. The GSRP principal investigator focused his efforts on investigating HITPERM compositional variants and annealing techniques to reduce the core loss without causing a significant decrease in either the saturation induction or operating temperature. The GSRP work was part of a Ph.D. thesis project and the dissertation was completed in December 2003 (ref. 19). Additional work, not reported in the dissertation, investigated the effect of various types of anneals, including transverse magnetic field anneal, on the core loss for several of the HITPERM alloys discussed in the dissertation. The results of this work were recently presented at the 49th Conference on Magnetism and Magnetic Materials (ref. 20). In this paper the authors conclude that magnetic field annealing reduces the core loss more effectively in the nanocrystalline HITPERM alloys than in the amorphous state but, unfortunately, no supporting core loss data was included in the paper to enable a comparison to presently available thin tape polycrystalline Cobalt-Iron alloys known in the industry as Supermendur or Hyperco 50.

Finally, the NASA sponsored nanocomposite work will be briefly reviewed along with the present status of this work. A nanocomposite magnetic material consists of a core (magnetic metal) — shell (electrical insulator) nanostructure. The main nanocomposite processing steps are: synthesis of magnetic nanoparticles, coating of nanoparticles with electrical insulator, and consolidation or compaction of the insulated nanoparticles (powder) into a solid of near theoretical density to produce bulk materials with different shapes and sizes. Synthesis methods include chemical, sol-gel, plasma arc, and high-energy ball milling. Coating the magnetic nanoparticle electrically passivates the particle's surface and serves three very important purposes: (1) prevents oxidation since the particles are extremely chemically reactive and pyrophoric at ambient conditions, (2) develops a significant barrier to eddy currents by increasing the nanostructure resistivity, and (3) hinders grain growth or particle agglomeration of the insulated particles during compaction at high temperature.

The consolidation of the nanocomposite powder into a solid is the critical step in developing the soft magnetic properties (i.e., low coercivity and high permeability) in a nanocomposite solid magnetic material. An isolated nanocomposite particle possesses very high anisotropy and demagnetizing effect. An isolated particle has an effective permeability of unity. For a nanocomposite magnetic material to exhibit soft magnetic properties requires that the magnetic moments of neighboring particles be magnetically coupled by what is known as magnetic moment exchange coupling. A critical parameter, the exchange coupling length, is the distance within which the magnetic moments of the neighboring particles can be coupled. If the distance between the neighboring particles is greater than the exchange length, i.e., poor compaction of the powder, then a nanocomposite magnetic solid will result with poor soft magnetic properties.

The consolidation or compaction process used must be capable of making the particle separation distance less than the critical exchange coupling length. Each magnetic alloy has its own critical exchange coupling length. Consolidation methods include sintering, hot press, hot isostatic press, detonation compaction, dynamic magnetic compaction, and electro-discharge compaction. The difficulty involved in any consolidation technique lies in obtaining full densification of the particle assembly without destroying the nanostructure of the particles. To produce nanocrystalline solids with acceptable soft magnetic properties require that the nanoparticles be exchanged coupled with their neighbors. Thus, any synthesis process used to produce free standing nanoparticles must use a compaction technique in which full densification of the solid occurs and the coated magnetic nanoparticles end up exchange coupled.

It should be noted that a very important advantage of nanocomposite over nanocrystalline magnetic materials is that nanocomposite core fabrication begins with a powder just like ferrites. Nanocrystalline materials start with amorphous precursor thin tapes and remain so after being partially crystallized. Ferrite cores come in many different shapes and sizes and so nanocomposite magnetic materials should likewise be capable of producing various sizes and shapes not achievable with nanocrystalline magnetic tapes. The potential advantage of the nanocomposite over the ferrite is that the nanocomposite has the potential to have higher saturation induction, higher operating temperature, and lower core loss than the power ferrites.

NASA's nanocomposite sponsored soft magnetic materials research was funded under two Phase II SBIR's and both of these are now completed. Each company used different synthesis, nanoparticle, passivation process, and compaction techniques. The compaction process proved to be much more challenging than initially anticipated as the desired packing density of near 100 percent was not fully realized. Because of this, the coercivity, which is an excellent measure of the "softness" of a magnetic alloy, was higher than comparable commercially available materials such as Supermendur or Hyperco 50 for polycrystalline Cobalt-Iron-Vanadium alloys or Permalloy for Nickel-Iron-Molybdenum alloys. 


\section{Dielectrics and Capacitors}

Capacitors are generally divided into three main groups: electrostatic, electrolytic, and electrochemical. Electrostatic capacitors are of main interest in this discussion. They consist of paper and polymer films, ceramic, and mica. Paper and polymer film capacitors are further broken down into metallized and film-foil construction. Although a capacitor is simply a set of metal electrodes with a dielectric material stuck in between them, the technology to develop higher performance, high temperature dielectric is far from simple. Table 4 gives a listing of desired capacitor dielectric properties. Just as for soft magnetic materials, the chance of finding all these desirable properties in any given dielectric material is very low.

TABLE 4.-CAPACITOR DIELECTRIC DESIRED PROPERTIES

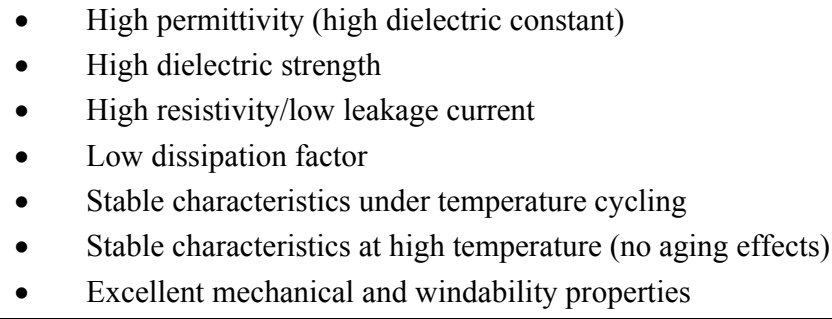

A comparison of two of these properties, dielectric constant and dielectric strength (voltage per unit dielectric thickness), is given in table 5 for several different dielectrics. Polymer film and ceramic capacitors make up much of the commercial electrostatic market. A comparison of these two dielectrics in table 5 shows that polymer films have relatively low dielectric constants and high dielectric strengths while ceramics have just the opposite

TABLE 5.-DIELECTRIC CONSTANT AND DIELECTRIC STRENGTH OF SELECT DIELECTRIC MATERIALS

\begin{tabular}{|l|l|l|}
\hline Material & Dielectric constant & $\begin{array}{l}\text { Dielectric strength } \\
\text { (V/mil) }\end{array}$ \\
\hline Air & 1.0 & 75 \\
Kraft paper (imp.) & 4.0 & 2,000 \\
Polymers & 2.5 to 3.0 & 5,000 to 9,000 \\
Mica & 5.4 to 8.7 & 1,400 \\
Glass & 3.0 to 4.5 & 500 \\
Tantalum pentoxide & 26 & - \\
Aluminum oxide & 7.0 & 300 \\
Ceramics & 12 to 400,000 & 200 to 350 \\
\hline
\end{tabular}

Two figures of merit commonly used in capacitor technology are volumetric efficiency and energy density. The volumetric efficiency is usually used for filter capacitors and the energy density for storage and pulse capacitors. Capacitance $C$ is defined as:

where

$$
C=\frac{\varepsilon A}{t}=\frac{\varepsilon_{0} \varepsilon_{r} A}{t} \quad \text { Farad }
$$

$$
\begin{aligned}
& \varepsilon=\varepsilon_{r} \varepsilon_{0}=\text { permittivity } \\
& \varepsilon_{0}=\text { Free space permittivity } \\
& \varepsilon_{r}=\text { Relative permittivity } \\
& A=\text { Dielectric surface area } \\
& t=\text { Dielectric thickness }
\end{aligned}
$$

$$
\begin{aligned}
& \text { Farad } / \text { meter } \\
& =8.85 \times 10^{-12} \text { Farad } / \text { meter } \\
& \text { dimensionless } \\
& \text { meter }^{2} \\
& \text { meter }
\end{aligned}
$$

For comparing just the volumetric efficiency of the capacitor dielectric, equation (1) is divided by the dielectric volume, $(\mathrm{Vol})_{d}$, to give:

$$
\frac{C}{(\mathrm{Vol})_{d}}=\frac{\varepsilon_{0} \varepsilon_{r}}{t^{2}} \quad \text { Farad }
$$


where

$$
(\mathrm{Vol})_{d}=A t \quad \text { meter }
$$

Equation (2) shows the dielectric volumetric efficiency can be increased by increasing $\varepsilon_{r}$ or decreasing $t$ and because $t$ is squared, this appears to be the best approach but the limit for decreasing $t$ is the dielectric strength. As the rated capacitor voltage increases, so also must the dielectric thickness so as not to cause voltage breakdown by exceeding the material's dielectric strength.

The volumetric efficiency for commercially packaged capacitors using an electrolytic, polymer film, and ceramic dielectric is given in table 6 . In this table the volume is that of the packaged capacitor. The table shows for the $100 \mathrm{~V}$ capacitors that the wet tantalum has the highest volumetric efficiency followed by the aluminum electrolytic, then the Z5U Multi-Layer Ceramic Capacitor (MLCC), and finally the metallized polyester film capacitor for the film types. This comparison is really not a fair comparison because when doing a volumetric efficiency comparison, not only should the voltage be the same, but also the capacitance. But finding capacitors which are constructed from different dielectric materials with the same capacitance and voltage rating is practically impossible.

TABLE 6.-CAPACITOR VOLUMETRIC EFFICIENCY FOR DIFFERENT TYPES OF DIELECTRICS

\begin{tabular}{|l|c|c|c|}
\hline \multicolumn{1}{|c|}{ Type } & $\begin{array}{c}\text { Capacitance, } \\
(\boldsymbol{\mu F})\end{array}$ & $\begin{array}{c}\text { Voltage, } \\
(\mathbf{V})\end{array}$ & $\begin{array}{c}\text { C/Vol, } \\
\left(\boldsymbol{\mu} \mathbf{F} / \mathbf{c m}^{\mathbf{3}}\right)\end{array}$ \\
\hline Wet tantalum & 120 & 100 & 62 \\
Solid tantalum & 10 & 100 & 8.9 \\
Al electrolytic & 18,000 & 100 & 48 \\
\hline Polyester film-foil & 3 & 100 & 0.22 \\
Polyester film-foil & 3 & 200 & 0.12 \\
Metallized polyester & 10 & 100 & 1.13 \\
Metallized polyester & 10 & 250 & 0.66 \\
\hline COG/NPO & 12 & 100 & 0.3 \\
X7R & 120 & 100 & 4.5 \\
X7R & 120 & 200 & 3.0 \\
Z5U & 720 & 100 & 18 \\
\hline
\end{tabular}

It is of interest to see how capacitors with the same capacitance but different voltage rating compare in volumetric efficiency. In table 6 three cases are listed. The volumetric efficiency of the $3 \mu \mathrm{f}, 200 \mathrm{~V}$ polyester filmfoil capacitor decreases by 45 percent compared to the $100 \mathrm{~V}$ capacitor. For the metallized polyester $10 \mu \mathrm{f}$ capacitor, the volumetric efficiency of the $250 \mathrm{~V}$ capacitor decreases by 42 percent compared to the $100 \mathrm{~V}$ capacitor. In the case of the $120 \mu \mathrm{f}$ ceramic X7R capacitor, the volumetric efficiency of the $200 \mathrm{~V}$ capacitor decreases by 33 percent compared to the $100 \mathrm{~V}$ capacitor. In all three cases the volumetric efficiency decreases as the voltage increases for the same capacitance but the ceramic capacitor had the smallest decrease compared to the film capacitors. The reason for this decrease in volumetric efficiency can be seen from equation (2). The higher voltage rated capacitors need a thicker dielectric layer to prevent voltage breakdown and as equation (2) shows, an increase in dielectric thickness will cause a decrease in the volumetric efficiency of the dielectric with a resultant increase in the volume of the packaged capacitor.

The other figure of merit, energy density, is defined as the energy per unit volume. The energy, $E$, stored in a capacitor is given by:

$$
E=\frac{1}{2} C V^{2} \quad \text { Joule }
$$

where

$$
V=\text { Rated Voltage } \quad \text { Volts }
$$

Energy density of a capacitor is defined as the energy per unit volume or mass, and just as in the definition of volumetric efficiency, energy density includes not only the dielectric but also the electrodes and package. For comparing just the energy density of the capacitor's dielectric, equation (3) is divided on both sides by (Vol $)_{d}$ to give: 


$$
\frac{E}{(\mathrm{Vol})_{d}}=\frac{1}{2} \frac{\varepsilon_{0} \varepsilon_{r} V^{2}}{(\mathrm{Vol})_{d}}=\frac{1}{2} \frac{\varepsilon_{0} \varepsilon_{r} V^{2}}{t^{2}} \quad \text { Joule/meter }{ }^{3}
$$

Equation (4) shows that the energy density is proportional to the product of the volumetric efficiency and voltage squared. A capacitor with high volumetric efficiency capable of operating at high voltage will have high energy density. Equation (4) clearly shows that the means to a high energy density capacitor is a high operating voltage and trade-off here is dielectric strength versus operating voltage to achieve the minimum dielectric thickness.

NASA GRC's sponsored capacitor research is presently in polymer, ceramic, and diamond-like-carbon (DLC) dielectrics. The emphasis of this work is on high/wide temperature and high volumetric efficient power filter capacitors. Developing new materials to increase the volumetric efficiency and energy density is a challenge, but perhaps a bigger challenge is the development of high temperature $\left(>200^{\circ} \mathrm{C}\right)$ capacitors capable of long-life and high reliability beyond the temperatures $\left(85\right.$ to $\left.125^{\circ} \mathrm{C}\right)$ of most commercial capacitors. The capacitor is presently considered the weakest link in the development of high temperature PMAD subsystems.

The polymer capacitor work consists of two projects: one is a NASA SBIR and the other is work in collaboration with the Air Force. The objective of the NASA SBIR work is to enhance the dielectric and electrical properties of polypropylene capacitor film through molecular dispersion of inorganic additives to increase the dielectric constant and dielectric strength and maintain a low dissipation factor. The Phase I was completed and during Phase I the contractor demonstrated improved nanocomposite dielectric films with increases in dielectric strength, dielectric constant, and operating temperature. Prototype wound film capacitors were also fabricated and tested. A Phase II was awarded and the contractor has completed about six months of the contract. The proprietary nature of this work does not allow a more detailed discussion of the present results at this time.

The other NASA sponsored polymer dielectric work is with the Air Force Research Laboratory (AFRL) and this effort is being lead by the Electrical Technology and Plasma Physics Branch at Wright Patterson Air Force Base (WPAFB). The new capacitor grade polymer being developed is known as Fluorene Polyester (FPE) which is inorganic aromatic polyester with repeating, interpolymerized units derived from isophthalic acid (hydroxyphenyl) fluorine (ref. 21). FPE has a glass transition temperature of $325^{\circ} \mathrm{C}$ and has stable electrical, mechanical, and optical properties at temperatures of $250^{\circ} \mathrm{C}$ or more. The FPE resin is supplied by Ferrania and Brady Worldwide, Inc. has developed a solvent based casting process to manufacture capacitor grade films in the 2 to $5 \mu \mathrm{m}$ thickness range. The FPE films are metallized by Steinfilm Inc., and then wound into capacitors and tested by Dearborn Electronics, Inc. (ref. 21). NASA GRC has recently received 24 developmental type filter capacitors fabricated from $5 \mu \mathrm{m}$ FPE film for test and evaluation at room and elevated temperatures up to $200{ }^{\circ} \mathrm{C}$ or more. The delivered capacitors are rated at $17 \mu \mathrm{F}$ and $250 \mathrm{VDC}$.

The ceramic capacitor dielectric work is being done under a grant to the Materials Research Institute, Pennsylvania State University (PSU), and a NASA SBIR. The focus of the research with PSU was on exploring, developing, and characterizing a range of ceramic compositions in the $\mathrm{Pb}\left(\mathrm{Zr}_{\mathrm{x}}-\mathrm{Ti}_{1-\mathrm{x}}\right) \mathrm{O}_{3}$ system, commonly referred to as PLTZ. This ceramic composition system has significantly higher Curie temperatures then the $\mathrm{BaTiO}_{3}$ system and should allow for fabricating high temperature Multilayer Ceramic Capacitors (MLCCs). The $\mathrm{BaTiO}_{3}$ system is the ceramic composition used in most commercial MLCCs. Multilayer ceramic test capacitors with layers of different transition temperatures were successfully fabricated by controlling the heating rate and annealing atmosphere. The test capacitors were used to measure high and low field ac field dielectric constant, dc bias dependence of dielectric response, conductivity, and reliability. A major emphasis of this work was to investigate long-term failure mechanisms associated with electrochemical, electromigration, and electro-mechanical effects. This failure mechanism investigation was mostly done by using the Highly-Accelerated-Lifetime-Test (HALT) in which the leakage currents were monitored at elevated temperatures and high electric fields. Using parameters from the HALT test, a model was developed to predict volumetric capacitance as a function of lifetime expectancy and operating voltage. The grant work has been completed and the results were presented at the HiTECH 2004 conference (ref. 22).

The objective of the NASA SBIR capacitor ceramic dielectric work is to develop a new family of relaxor ferroelectric materials capable of operating at high voltage over a very wide temperature range. The relaxor ferroelectric developed in Phase I was based on the recently discovered $\mathrm{BiMe}_{3}-\mathrm{PbTiO}_{3}(\mathrm{BPT})$ where $\left(\mathrm{Me}=\mathrm{Sc}^{3+}\right.$, $\left.\mathrm{Yb}^{+}, \mathrm{Fe}^{3+},---\right)$ family of morphotropic phase boundary containing perovskites (refs. 23 and 25). Relaxor ferroelectrics have a broad diffuse ferroelectric-to-paraelectric transition. The ferroelectric domains are nano-sized with unstable polarization and very low loss under high ac drive conditions near the transition temperature (refs. 25 and 26). The choice of the relaxor ferroelectric composition will determine the capacitance frequency dependence, dielectric loss, and operating temperature. The Phase I objective was successfully met and the feasibility of 
fabricating high temperature $\left(300^{\circ} \mathrm{C}\right)$, high voltage $(500 \mathrm{~V})$, and high volumetric efficiency $\left(>1 \mu \mathrm{F} / \mathrm{cm}^{3}\right)$ MLCCs was clearly demonstrated. Presently commercially available MLCCs of similar voltage rating have operational temperatures of about one-half of several types of MLCCs fabricated in Phase I. The capacitance of ferroelectric MLCCs is voltage dependent. In general, as the voltage increases, the capacitance decreases due to a decrease in permittivity. Of very high significance was the experimental demonstration in Phase I of a MLCC fabricated from a BPT variant that exhibited less than 2 percent change in capacitance under an applied voltage over the range of 0 to $500 \mathrm{VDC}$ at $300{ }^{\circ} \mathrm{C}$. A phase II SBIR was awarded to further develop and package high/wide temperature MLCCs and this work is presently coming to a conclusion in the near future. Again, proprietary considerations do not allow a detailed discussion of work so far completed under Phase II. The results of Phase I were presented at CARTS 2004 (ref. 25) and HiTEC 2004 (ref. 26).

NASA GRC sponsored research with the Electrical Technology and Plasma Physics Branch at WPAFB to develop a prototype manufacturing technology to produce high quality capacitor grade DLC films on aluminum for fabricating high voltage, high temperature, and high volumetric efficient and high energy density capacitors. DLC is an amorphous film and possesses the unique properties of high dielectric strength, high resistivity, high decomposition temperature, low loss, chemical inertness, and good thermal conductivity. These very desirable properties make DLC films of high interest for capacitor applications. DLC also offers very smooth, flexible films which can be deposited directly on aluminum foils or aluminum coated polymer film with excellent adhesion and with very thin coating thickness. The production of DLC coated aluminum foils at WPAFB uses a dual hydrocarbon ion beam deposition system. The gases normally used are methane and hydrogen. The aluminum foil coating system, i.e., the web-handling system, utilizes a closed loop servo-drive system to control foil tension and speed. The system is capable of operating in both forward and reverse directions. Through tension and speed control, a long length of DLC film deposited on both sides of the aluminum foil can be produced. By depositing the DLC film on both sides of the aluminum foil, the undesirable effect of pin holes is greatly reduced. Pin holes create an air gap between adjacent layers of the capacitor's electrodes. The dielectric constant of air is unity which is less than the dielectric film, so the greatest voltage stress is across the air gap and as a result, voltage break down occurs with subsequent capacitor failure.

Recent experimental results (refs. 27 and 28) show that typical DCL films which contain about 60 at.\% carbon and 40 at.\% hydrogen have a dielectric constant about 3.5, breakdown voltage strength greater than $650 \mathrm{~V} / \mu \mathrm{m}$ $(16.5 \mathrm{kV} / \mathrm{mil})$ and a de resistivity greater than $10 \Omega \mathrm{cm}$ (ref. 14). A wound DLC prototype capacitor was recently fabricated and its capacitance as a function of frequency over the temperature range of -50 to $250{ }^{\circ} \mathrm{C}$ was characterized. The capacitance values from -50 to $250{ }^{\circ} \mathrm{C}$ were found to be constant from about $100 \mathrm{~Hz}$ to about $500 \mathrm{kHz}$ with the capacitance decreasing at the upper frequency and increasing at the lower frequency. The work under this program is now being supported by an Air Force Phase III SBIR. The main objective of the Phase III program is to (1) transfer the DLC manufacturing technology developed under the Air Force SBIR Phase II program and the NASA sponsored work to a commercial manufacturer to scale up the production process of high quality DLC films and (2) have a commercial capacitor manufacturer design and fabricate high volumetric and high energy density capacitors for filter and pulse power applications. The transition to commercial manufacturers for both the production of DLC film and capacitors was recently completed with present emphasis on manufacturing DLC film capacitors on a large scale production.

\section{Wide Bandgap Semiconductor Materials}

PMAD subsystems that simultaneously require high temperature, high voltage, and high power operation will require the use of wide bandgap semiconductor switches (MOSFETs, IGBTs, BJTs, and Thyristors, etc.) and diodes (pn junction and Schottky). Semiconductor devices that can function at temperatures beyond 150 to $175{ }^{\circ} \mathrm{C}$ without external cooling could greatly benefit not only future aerospace power systems but also the automotive and energy production industries. Present high power and high voltage semiconductor devices use silicon ( $\mathrm{Si}$ )-based technology. The high density of intrinsic carriers of Si at elevated temperatures make high power, high voltage Si devices not useable above 150 to $175^{\circ} \mathrm{C}$.

Silicon carbide ( $\mathrm{SiC}$ )-based and III-nitride-based devices (primarily $\mathrm{GaN}$ ) are the most developed wide bandgap semiconductors but many issues require resolution. NASA GRC sponsors both $\mathrm{SiC}$ and $\mathrm{GaN}$ research but the primary emphasis is on the development of $\mathrm{SiC}$ power devices so this section will be limited to a discussion of $\mathrm{SiC}$. $\mathrm{SiC}$ is the most mature wide bandgap material, in terms of the development of high temperature, high voltage power devices. Some of the major advantages of $\mathrm{SiC}$ compared to $\mathrm{Si}$ are the following: 
1. SiC has a critical electric field of about 10 times or more (depending on polytype) compared to Si. This advantage results in higher device breakdown voltage capability and thus drift regions and voltage hold-off layers can be thinner.

2. $\mathrm{SiC}$ device die are thinner because of the above advantage of high breakdown voltage. Thinner die mean lower on-state resistance.

3. $\mathrm{SiC}$ can have higher doping, again because of the higher breakdown voltage capability. This situation also leads to lower on-state resistance and lower conduction losses and, therefore, higher efficiency.

4. $\mathrm{SiC}$ has a thermal conductivity almost 2 times greater than $\mathrm{Si}$. This gives a lower junction-to-case thermal resistance because heat is more easily conducted from the device junction(s) with a resultant decrease in temperature rise.

5. SiC can operate at high temperature because of its wider bandgap and thus reduces or possibly eliminates the need for external cooling.

The present consensus seems to be that $\mathrm{SiC}$ devices will be used in a large number of applications once they become commercially available. Presently the only commercially available SiC devices are Schottky diodes and Cree (ref. 29), Infineon Technologies AG (ref. 30), Microsemi (ref. 31), and Solid State Devices (ref. 32) have a product line for these devices. The introduction of other $\mathrm{SiC}$ devices such as power switches into the commercial market will require the resolution of many technical issues including material quality, contacts, $\mathrm{SiC} /$ oxide interface, passivation, and packaging.

In $\mathrm{SiC}$ materials the presence of device-killing defects such as micropipes as well as densely populated screw dislocations is a critical issue requiring resolution. Power devices require large area substrates and until the material's issue is solved, present $\mathrm{SiC}$ technology will be limited to low current devices. Another challenge is developing durable and reliable metal-semiconductor contacts and interconnects because poor quality contacts are a primary limiting factor for high temperature operation of power devices. The present quality of the SiC/oxide interface is a fundamental problem because it prevents bringing gated devices such as MOSFETs and IGBTs to the commercial market. Quality passivants are also needed to prevent surface leakage and high voltage breakdown at junction interfaces. Another hurdle to surmount is high temperature packages capable of reliable operation at temperatures $>200{ }^{\circ} \mathrm{C}$. Major technical challenges to realize high temperature packages include chemical, mechanical, and electrical stability of both packaging materials as well as the interfaces between these materials. For a more detailed discussion of these technical issues the reader is referred to references 33 and 34 .

The development of $\mathrm{SiC}$ crystal growth and device fabrication technology is presently based on the hexagonal $4 \mathrm{H}$-and $6 \mathrm{H}-\mathrm{SiC}$ polytypes. Mass produced wafers of these polytypes with reasonable size and quality have been commercially available for over a decade. Improving the quality of $4 \mathrm{H}$-and $6 \mathrm{H}-\mathrm{SiC}$ wafers is an on-going effort and various approaches are being investigated. The Advanced Electrical Components Technology Task has sponsored research with the Sensors and Electronics Technology Branch, NASA GRC, to investigate a new approach to develop higher quality $4 \mathrm{H}$ - and $6 \mathrm{H}-\mathrm{SiC}$ substrates and also to grow $3 \mathrm{C}-\mathrm{SiC}$ films on these substrates. In the past few years as both commercial and developmental $\mathrm{SiC}$ power devices have become available, more effort has been directed at the characterization and evaluation of these devices with particular emphasis on dynamic characterization at elevated temperatures. A brief review of the past $\mathrm{SiC}$ substrate work will now be given and then followed by a summary of the present in-house work being conducted on the characterization of $\mathrm{SiC}$ devices.

The NASA GRC research team has demonstrated the growth of step-free surfaces on device-size SiC mesas (ref. 35). This new growth process to produce atomically smooth or flat surfaces is called "step-free surface heteroepitaxy". On commercial $4 \mathrm{H}-\mathrm{SiC}$ wafers, step free mesas with dimensions up to $200 \mu \mathrm{m}$ square have been demonstrated while on a $6 \mathrm{H}-\mathrm{SiC}$ wafer, step free mesas with dimensions up to $50 \mu \mathrm{m}$ have been produced (ref. 36). This new homoeptaxial growth process is performed on the mesas under conditions that promote step-flow growth and at the same time suppress 2D nucleation on the mesa top. A description of this process is given in reference 35 .

The density of screw dislocations in the $\mathrm{SiC}$ wafers is a limiting factor in scaling up the size and yield of the step free mesas. The mesas containing screw dislocations could not be made step free because of the continual spiral of new growth steps emanating from the screw dislocations during the homoepitaxial growth process. To overcome this deficiency in the growth process, the research team has developed a SiC homoepitaxial lateral "web growth" process (ref. 35). Experimental analysis of the webbed regions formed over a micropipe and closed-core screw dislocations show that c-axis propagation of these defects is terminated by the "web growth" process (ref. 37). The present "web growth" process is not considered to be optimized but webbed surfaces as large as $4 \times 10^{-3} \mathrm{~cm}^{2}$ have been grown. This area represents more than 4 times the pre-growth mesa area (ref. 36). For the interested reader, an excellent review of homoepitaxial and heteroepitaxial growth on step-free $\mathrm{SiC}$ mesas is given in reference 38 . 
The growth of defect free $3 \mathrm{C}-\mathrm{SiC}$ on $4 \mathrm{H}$-and $6 \mathrm{H}-\mathrm{SiC}$ mesas has been demonstrated using the new step free surface heteroepitaxial growth process (ref. 39). A detailed structural characterization of 3C-SiC heteroepitaxial films grown on 4 step-free $4 \mathrm{H}$-and $6 \mathrm{H}$-Sic mesa surfaces was recently done. The results of this investigation suggest that step free surface heteroepitaxy enables benign partial lattice mismatch strain relief during heterofilm growth (ref. 40). The ability to produce high quality $3 \mathrm{C}-\mathrm{SiC}$ heteroepitaxial films free from extended crystal defects could enable the development of $\mathrm{SiC}$ switches and diodes with significantly improved performance ratings in voltage, current, temperature, and on-state losses.

From the above discussion it is recognized that the quality of presently available $\mathrm{SiC}$ substrates must be improved or techniques devised to "engineer" a higher quality substrate, such as "step-free surface heteroepitaxy" in order to enable the development of high voltage and high power $\mathrm{SiC}$ diodes and switches. It is also recognized that $\mathrm{SiC}$ devices available either commercially or as developmental prototypes must be tested to determine their static and dynamic operating characteristics and limitations in order to evaluate the quality of material on device performance. Also, these devices must also be inserted into circuit topologies, such as DC-DC converters, in order to determine their performance characteristics and failure modes under different operating conditions. In the past few years NASA GRC has initiated a task to test, characterize, and evaluate available $\mathrm{SiC}$ devices with respect to their static and dynamic performance as well as their performance in circuit applications. The design and fabrication of specialized test circuits to conduct static and dynamic tests at elevated temperatures, along with the equipment and measurement systems required to operate these circuits, is a major effort of the in-house $\mathrm{SiC}$ characterization work.

Commercially available SiC Schottky diodes from three different vendors were tested in-house (ref. 41) under steady state conditions. Switching transient tests were also performed using some of these same diodes in a hard switched DC-DC "buck" converter. Silicon (Si) Schottky, Gallium Arsenide (GaAs) Schottky, and Si pn-junction diodes were also tested to enable a comparison to the steady state and transient characteristics of the SiC Schottky diodes. The results of the steady state characterization tests show that commercially available Si ultra-fast pnjunction diodes show better forward and reverse characteristics at rated current and voltage than the SiC Schottky diodes. However, $\mathrm{SiC}$ has made possible the availability of new high voltage 300, 600, and $1200 \mathrm{~V}$ Schottky diodes that are not available in Si. The advantage of the SiC Schottky diodes over the ultra-fast pn-junction diodes lies in their superior reverse recovery transient behavior. This superior transient behavior results in significant reductions in diode switching losses at high frequencies. The higher frequency operation enables the development of high power density switching converters because of mass/volume reductions in the passive components. Another significant advantage of $\mathrm{SiC}$ devices is their capability to operate at much higher temperatures than $\mathrm{Si}$ devices.

A number of commercial SiC Schottky diodes were tested under steady state and transient conditions and compared with ultra fast Si pn-junction diodes for temperature up to $200{ }^{\circ} \mathrm{C}$ (ref. 42). Again, the ultra fast Si pnjunction diodes outperformed the $\mathrm{SiC}$ Schottky diode's forward voltage drop at rated current for temperature range investigated. At rated current, the Si pn-junction diode's forward voltage drop decreased as a function of temperature while the forward voltage drop of the SiC Schottky diode increased with temperature due to the device's bulk resistance. For the steady state reverse I-V tests over the temperature range investigated, the $\mathrm{SiC}$ Schottky diodes showed superior reverse voltage blocking capabilities compared to the ultra fast Si pn-junction diodes. This was expected because $\mathrm{SiC}$ has a larger band gap than $\mathrm{Si}$. The generation of intrinsic carriers for reverse voltage depends on both bandgap and temperature. In the transient tests using a "buck" converter, the SiC Schottky diodes displayed lower peak reverse recovery currents and faster recovery times than the ultra fast Si pn-junction diodes over the temperature range of 25 to $150{ }^{\circ} \mathrm{C}$. The SiC Schottky diodes showed no noticeable change in the peak reverse recovery currents and recovery times with increasing temperature while the Si pn-junction diodes showed increasing peak reverse recovery currents and recovery times as the temperature increased. In the "buck "converter efficiency tests conducted at room temperature and the lowest switching frequency of $40 \mathrm{kHz}$, the efficiency of the SiC Schottky diode converter was comparable to the efficiency of the ultra fast Si pn-junction diode converter. But as the temperature and converter switching frequency increased to $200{ }^{\circ} \mathrm{C}$ and $150 \mathrm{kHz}$, respectively, the efficiency of the $\mathrm{SiC}$ Schottky diode converter became significantly better than the ultra fast $\mathrm{Si}$ pnjunction diode converter. The advantage of using $\mathrm{SiC}$ Schottky diodes for high temperature and high frequency operation was clearly demonstrated.

An investigation was recently conducted on the static and turn-on characteristics of normally-off $\mathrm{SiC}$ static induction transistors (SITs), also sometimes referred to as vertical, short-channel, junction field-effect transistors (VJETs), to $200{ }^{\circ} \mathrm{C}$ (ref. 43). These were developmental type devices designed and fabricated by United Silicon Carbide, Inc. Sits commercially produced years ago were all normally-on devices, with characteristics resembling those of a triode vacuum tube. Power switching circuit designers in general prefer normally-off semiconductor switches because under loss of power the switches turn-off and thus prevent circuit failure. The SiC SITs evaluated were rated at $600 \mathrm{~V}$ and $3 \mathrm{~A}$. Static I-V characteristic curves and pulse mode turn-on switching tests were done at 
several temperatures up to $200^{\circ} \mathrm{C}$. The results of this experimental investigation will be presented at IECEC 2005 (ref. 43). Recently, SiC developmental Bipolar Junction Transistors (BJTs) were obtained and testing of these devices is now underway.

\section{Conclusion}

Future space power systems for spacecraft and lunar and planetary surface power will require the availability of high performance electrical components in the PMAD subsystem. The primary means to develop these advanced, high performance components is to develop new and significantly improved materials for magnetic components, capacitors, and semiconductor switches and diodes. The emphasis of NASA GRC's Advanced Electrical Component Technology task is to develop high performance components capable of higher power/energy density, higher voltage and higher temperature operation, higher efficiency, and higher radiation tolerance. The purpose of the paper is to give (1) the motivation for developing advanced electrical materials and components by delineating the benefits for both the PMAD subsystem and the power system, (2) the rationale for selecting the magnetic, dielectric, and semiconductor materials being investigated and developed and the prior theoretical or experimental research to justify the selection, and (3) the status of the work being done internally, through partnerships, and contract and grant sponsorship.

\section{References}

1. Schwarze, G.E., "Advanced Electrical Materials and Component Development," First International Energy Conversion Engineering Conference," Portsmouth, Virginia, August 17-21, 2003.

2. Weiserman, W.R., G.E. Schwarze, and J.M. Niedra, "Comparison of High Frequency, High Temperature Core Loss and B-H Loop Characteristics of an $80 \mathrm{Ni-Fe}$ Crystalline Alloy and two Iron-Based Amorphous Alloys," Eighth Symposium on Space Nuclear Power Systems Proceedings, Part Three, Albuquerque, NM, January 6$10,1991$.

3. Weiserman, W.R., G.E. Schwarze, and J.M. Niedra, "Comparison of High Temperature, High Frequency Core Loss and Dynamic B-H Loops of Two 50 Ni-Fe Crystalline Alloys and an Iron-Based Amorphous Alloy," 26th Intersociety Energy Conversion Engineering Conference Proceedings, Boston, MA, August 4-9, 1991.

4. Weiserman, W.R., G.E. Schwarze, and J.M. Niedra, "Comparison of High Temperature, High Frequency Core Loss and Dynamic B-H Loops of a 2V-49Fe-49Co and a Grain Oriented 3Si-Fe Alloy," 27th Intersociety Energy Conversion Engineering Conference, San Diego, CA, August 3-7, 1992.

5. Schwarze, G.E., W.R. Weiserman, and J.M. Niedra, "Effects of Temperature, Frequency, Flux Density, and Excitation Waveform on the Core Loss and Dynamic B-H Loops of Supermalloy," 30th Intersociety Energy Conversion Engineering Conference, Orlando, FL, August 4, 1995.

6. Niedra, J.M. and G.E. Schwarze, "Wide Temperature Core Loss Characteristics of Transverse Magnetically Annealed Amorphous Tapes for High Frequency Aerospace Magnetics," 34th Intersociety Energy Conversion Engineering Conference, Vancouver, British Columbia, Canada, August 1-5, 1999.

7. Niedra, J.M., "Comparative Wide Temperature Core Loss Characteristics of Two Candidate Ferrites for the NASA/TRW 1500W PEBB Converter," NASA/CR-1999-209302 August 1999.

8. Magnetics, Tape Wound Cores Design Manual, TWC-500, 1998.

9. Schwarze, G.E., W.R. Wieserman, and J.M. Niedra, "Magnetic and Electrical Characteristics of Permalloy Thin Tape Bobbin Cores" Second International Energy Conversion Engineering Conference, Providence, RI, August 16-19, 2004.

10. Herzer, G., "Grain Size Dependence of Coercivity and Permeability in Nanocrystalline Ferromagnet, "IEEE Transactions on Magnetics, vol. 26, no. 5, September 1990, pp. 1397-1402.

11. Herzer, G., "Nanocrystalline Soft Magnetic Materials," Journal of Magnetism and Magnetic Materials". 112 (1992) 258-262.

12. Vacuumschmelze literature web site: http://www.vacuumschmelze.de/dynamic/en/

13. Niedra, J.M., G.E. Schwarze, "Wide Temperature Magnetization Characteristics of Transverse Magnetically Annealed Amorphous Tapes for High Frequency Aerospace Magnetics," 34th Intersociety Energy Conversion Engineering Conference, Vancouver, British Columbia, Canada, August 1-5, 1999. 
14. Wieserman, W.R., G.E. Schwarze, and J.M. Niedra, "Magnetic and Electrical Characteristics of Cobalt-Based Amorphous Material and Comparison to a Permalloy Type Polycrystalline Material" Third International Energy Conversion Engineering Conference, San Francisco, CA, August 15-18 2005.

15. Metglas ${ }^{\circledR}$ Technical Bulletin, www.metglas.com

16. Metglas ${ }^{\circledR}$ 2714A Cobalt Based Alloy, Material Safety Data Sheet, www.metglas.com

17. Willard, M.A., et al., "Structure and Magnetic Properties of $\left(\mathrm{Fe}_{0.5} \mathrm{Co}_{0.5}\right)_{88} \mathrm{Zr}_{7} \mathrm{~B}_{4} \mathrm{Cu}_{1}$ Nanocrystalline Alloys," Journal of Applied Physics, vol. 84, no. 12, December 15, 1998, 6773-6777.

18. Willard, M.A., et al., "Magnetic Properties of HITPERM (Fe, Co) ${ }_{88} \mathrm{Zr}_{7} \mathrm{~B}_{4} \mathrm{Cu}_{1}$ Magnets," Journal of Applied Physics, vol. 85, no. 8, 15 April, 1999, 4421-4423.

19. Johnson, F., "High-temperature and frequency-dependent properties and structural evolution of HITPERM, an Fe-Co-base nanocomposite soft ferromagnetic material," Ph.D. Dissertation, Department of Materials Science and Engineering, Carnegie Mellon University, Pittsburgh, PA, 2003.

20. Johnson, F., C.Y. Um, M.E. McHenry, and H. Garmestani, "The influence of composition and field annealing on magnetic properties of FeCo-base amorphous and nanocomposite alloys," 49th Conference on Magnetism and Magnetic Materials, Jacksonville, FL, November 7-11, 2004.

21. Carter, M.A., "Film Materials for High Temperature Operation," HiTEC 2004: International High Temperature Electronics Conference and Exhibition, Santa Fe, NM, May 17-20, 2004.

22. Furman, E.M., L.B. Jones, T. Shrout, S-Y Yoon, and G.E. Schwarze, "Dielectric Materials Development for High-Temperature Capacitors," HiTEC 2004: International High Temperature Electronics Conference and Exhibition, Santa Fe, NM, May 17-20, 2004.

23. Eitel, R.E., C.A. Randall, T.R. Shrout, P.W. Rehrig, W. Hackenberger, and Park S-E., "New High Temperature Morphotropic Phase Boundary Piezoelectric Based on $\mathrm{Bi}(\mathrm{Me}) \mathrm{O}_{3}-\mathrm{PbTiO}_{3}$ Ceramics," Jpn. J. Appl. Phys. vol .40 (2001) pp. 5999-6002, Part 1, no. 10, October 2001.

24. Eitel, R.E., C.A. Randall, T.R. Shrout, and Park S-E., "Preparation and Characterization of High Temperature Perovskite Ferroelectrics in the Solid-Solution (1-x)BiSc0 $0_{3}-\mathrm{xPbTi}_{3}$, , Jpn. J. Appl. Phys. vol. $41(2002$ pp. 2099-2104, Part 1, no. 4A, April 2002.

25. Alberta, E.F., W.S. Hackenberger, C.A. Randall, and T.R. Shrout, "High Temperature Ceramic Multilayer Capacitors," The 24th Capacitor and Resistor Technology Symposium (CARTS 2004), San Antonio, TX, March 29-April 1, 2004.

26. Alberta, E.F., W.S. Hackenberger, C.A. Randall, and T.R. Shrout, "High Temperature Ceramic Multilayer Capacitors," HiTEC 2004: International High Temperature Electronics Conference and Exhibition, Santa Fe, NM, May 17-20, 2004.

27. Wu, R.L., C.H. Kosai, M. Freeman, G.E. Schwarze, S. Fries Carr, and J.A. Weimer, "Thin Film Diamond-LikeCarbon Dielectrics," International Power Modulator Conference, Hollywood, CA, June 30-July 3, 2002.

28. Wu, R.L., C.H. Kosai, S. Fries Carr, J.A. Weimer, M. Freeman, and G.E. Schwarze, "Electronic Power System Application of Diamond-Like-Carbon Films," Proceedings of Seventh International Conference on Applied Diamond Films and Related Materials and 3rd International Conference on Frontier Carbon Technology (2003), Tsukuba, Japan, August 19-21, 2003.

29. Cree,http://www.cree.com/products/power/index.htm

30. Infineon Technologies AG-Products-Silicon Carbide Schottky Diode, http://www.infineon.com

31. Microsemi Products $>$ Power Conditioning $>$ Silicon Carbide (SiC) Schottky, http://www.microsemi.com

32. Solid State Devices, $\underline{\text { http://www.ssdi-power.com }}$

33. Neudeck, P.G., R.S. Okojie, and L. Chen, "High Temperature Electronics-A Role for Wide Bandgap Semiconductors," Proceedings of the IEEE, vol. 90, no. 6, pp. 1065-1076, June 2002.

34. Powell, J.A., L.B. Rowland, "SiC Materials-Progress, Status, and Potential Road Blocks," Proceedings of the IEEE, vol. 90, pp. 942-955, June 2002.

35. Powell, J.A., et al., "Growth of step-free surfaces on device-Size (0001) mesas," Applied Physics Letters, vol. 77, no. 10, pp. 1449-1451, 4 September, 2000.

36. Neudeck, P.G., et al., "Enlargement of step-free $\mathrm{SiC}$ surfaces by homoepitaxial web growth of thin $\mathrm{SiC}$ cantilevers," Journal of Applied Physics, vol. 92, no. 5, 1 September, 2002, pp. 2391-2400.

37. Neudeck, P.G., et al., "Homoepitaxial "Web Growth" of SiC to Terminate C-Axis Screw Dislocations and Enlarge Step-Free Surfaces," Materials Science Forum, vol. 389-393 (2002), pp. 251-254. 
38. Neudeck, P.G., J.A. Powell, "Homoepitaxial and Heteroepitaxial Growth on Step-Free SiC Mesas," Silicon Carbide Recent Advances, W.J. Choyke, H. Matsunami, and G. Pensl, eds., Heidelberg, Germany: SpringerVerlag, 2003, pp. 179-205.

39. Neudeck, P.G., et al., "Growth of Defect-Free 3C-SiC on 4H- and 6H-SiC Mesas Using Step-Free Surface Heteroepitaxy," Materials Science Forum, vol. 389-393 (2002), pp. 311-314.

40. Neudeck, P.G., et al., "Characterization of 3C-SiC Films Grown on 4H-and 6H-SiC Substrate Mesas during Step-Free Surface Heteroepitaxy,” Materials Science Forum vol. 433-436 (2003), pp. 213-216.

41. Lebron-Velilla, R.C., G.E. Schwarze, and S. Trapp, "Silicon Carbide Diodes Performance Characterization and Comparison with Silicon Devices," First International Energy Conversion Engineering Conference," Portsmouth, VA, August 17-21, 2003.

42. Lebron-Velilla, R.C., G.E. Schwarze, B.G. Gardner, J.D. Adams, Jr., "Silicon Carbide Diodes Characterization at High Temperature and Comparison with Silicon Devices," Second International Energy Conversion Engineering Conference, Providence, RI, August 16-19, 2004.

43. Niedra, J.M. and G.E. Schwarze, "Static and Turn-On Switching Characteristics of 4H-Silicon Carbide SITs to $200{ }^{\circ} \mathrm{C}$," Third International Energy Conversion Engineering Conference, San Francisco, CA, August 15-18, 2005. 


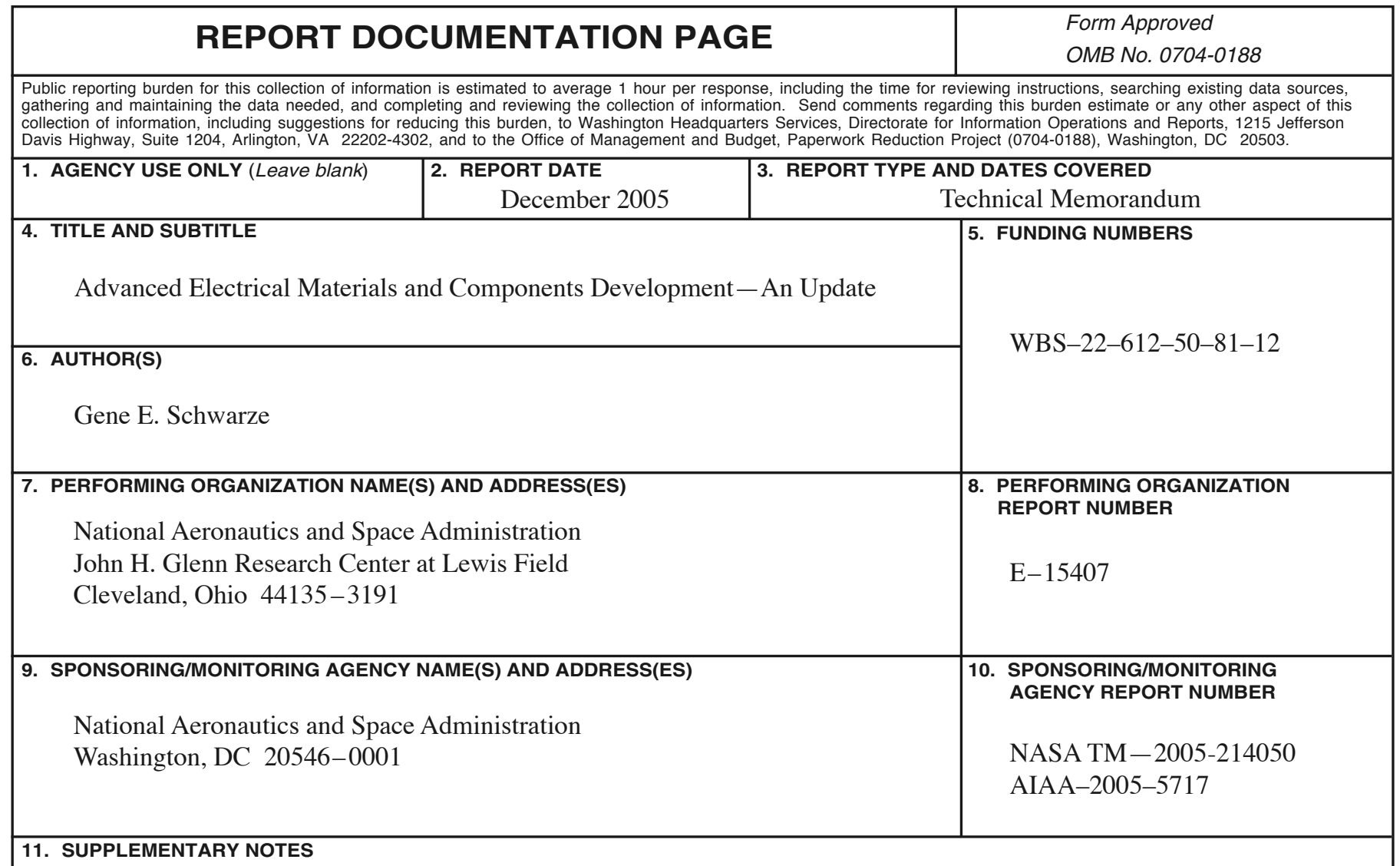

Prepared for the Third International Energy Conversion Engineering Conference sponsored by the American Institute of Aeronautics and Astronautics, San Francisco, California, August 15-18, 2005. Responsible person, Gene E. Schwarze, organization code RPE, 216-433-6117.

\begin{tabular}{|l|l}
\hline 12a. DISTRIBUTION/AVAILABILITY STATEMENT & 12b. DISTRIBUTION CODE
\end{tabular}

Unclassified - Unlimited

Subject Category: 33

Available electronically at http://gltrs.grc.nasa.gov

This publication is available from the NASA Center for AeroSpace Information, 301-621-0390.

13. ABSTRACT (Maximum 200 words)

The primary means to develop advanced electrical components is to develop new and improved materials for magnetic components (transformers, inductors, etc.), capacitors, and semiconductor switches and diodes. This paper will give an update of the Advanced Power Electronics and Components Technology being developed by the NASA Glenn Research Center for use in future Power Management and Distribution subsystems used in space power systems for spacecraft and lunar and planetary surface power. The initial description and status of this technology program was presented two years ago at the First International Energy Conversion Engineering Conference held at Portsmouth, Virginia, August 2003. The present paper will give a brief background of the previous work reported and a summary of research performed the past several years on soft magnetic materials characterization, dielectric materials and capacitor developments, high quality silicon carbide atomically smooth substrates, and SiC static and dynamic device characterization under elevated temperature conditions. The rationale for and the benefits of developing advanced electrical materials and components for the PMAD subsystem and also for the total power system will also be briefly discussed.

14. SUBJECT TERMS

Electrical components; Electronic components; Magnetic materials; Dielectrics; Capacitors; Silicon carbide devices; Silicon carbide materials

\begin{tabular}{|c|c|c|c|}
\hline $\begin{array}{c}\text { 17. SECURITY CLASSIFICATION } \\
\text { OF REPORT } \\
\text { Unclassified }\end{array}$ & $\begin{array}{c}\text { 18. SECURITY CLASSIFICATION } \\
\text { OF THIS PAGE } \\
\text { Unclassified }\end{array}$ & $\begin{array}{c}\text { 19. SECURITY CLASSIFICATION } \\
\text { OF ABSTRACT } \\
\text { Unclassified }\end{array}$ & 20. LIMITATION OF ABSTRACT \\
\hline
\end{tabular}

NSN 7540-01-280-5500

Standard Form 298 (Rev. 2-89)

Prescribed by ANSI Std. Z39-18 298-102 

